Departement für Kleintiere, Abteilung für Notfall- und Intensivmedizin der Vetsuisse Fakultät Universität Zürich

Vorsteher Departement für Kleintiere: Prof. med. vet. Antonio Pozzi, Dipl. ECVS / ACVS und ACVSMR

Abteilungsleiter: Dr. med. vet. Alessio Vigani, Dipl. ACVECC und ACVAA

Arbeit unter wissenschaftlicher Betreuung von

Dr. med. vet. Nadja E. Sigrist, FVH, Dipl. ACVECC und ECVECC

\title{
Serial Evaluation of Haemostasis Following Acute Trauma Using Rotational Thromboelastometry in Dogs
}

\author{
Inaugural-Dissertation \\ zur Erlangung der Doktorwürde der \\ Vetsuisse-Fakultät Universität Zürich \\ vorgelegt von
}

\section{Yaiza Herrero}

Tierärztin

von Häggenschwil

genehmigt auf Antrag von

Prof. Dr. med. vet. Antonio Pozzi, Dipl. ECVS/ACVS und ACVSMR, Referent 

Inhaltsverzeichnis

INHALTSVERZEICHNIS 3

ABSTRACT 4

ZUSAMMENFASSUNG 5

DANKSAGUNG

CURRICULUM VITAE 


\section{Abstract}

The aim of this study was to describe the coagulation status of traumatized dogs over the first 24 hours after admission.

In 33 dogs presenting within 6 hours after trauma blood was sampled for rotational thromboelastometry (ROTEM), thrombocyte number and venous blood gas analysis at presentation and 6 and 24 hours thereafter. At each time point, dogs were defined as hypo-, normo- or hypercoagulable based on extrinsic, intrinsic and fibrinogen ROTEM profiles.

Significantly more dogs (11/33) presented hypocoagulable compared with 6 hours $(p=0.046)$ and 24 hours $(p=0.008)$ thereafter and none presented hypercoagulable. Significantly more dogs were hypercoagulable $(6 / 23, p=0.014)$ and no dog was hypocoagulable at 24 hours compared with presentation. All evaluated ROTEM parameters except maximum lysis were significantly more hypocoagulable at presentation compared with 24 hours thereafter.

Hypocoagulability is more common in acutely traumatized dogs than previously described. Dogs were hypo- or normocoagulable at presentation and the coagulation status changed to normo- or hypercoagulability over the first 24 hours. Clotting times, clot formation and clot firmness but not clot lysis were significantly altered at presentation compared with 24 hours and fibrinogen concentration or function may play an important role in the dynamic change of coagulation state over time.

Coagulation, canine, hypercoagulopathy, ATC, acute traumatic coagulopathy 


\section{Zusammenfassung}

Unser Ziel war es, den Koagulations-Status von traumatisierten Hunden über die ersten 24 Stunden nach Spitaleintritt zu beschreiben.

In 33 Hunden, die innerhalb 6 Stunden nach Trauma als Notfall vorgestellt wurden, wurden Blutproben für Rotationsthromboelastometrie (ROTEM), Thrombozytenzahl und venöse Blutgas-Analyse bei Eintritt, nach 6, sowie 24 Stunden entnommen. Die Hunde wurden zu jedem Zeitpunkt, entsprechend ihrer extrinsischen-, intrinsischen- und Fibrinogen-ROTEM Profilen, als hypo-, normo- oder hyperkoagulabel definiert.

Signifikant mehr Hunde (11/33, 33\%) waren initial hypokoagulabel, im Vergleich zur 6 und 24 Stunden Messung $(p=0.046,0.008)$ und keiner war hyperkoagulabel. Nach 24 Stunden, waren signifikant mehr Hunde hyperkoagulabel $(6 / 23,27 \%, p=0.014)$ und keiner war hypokoagulabel. Alle von uns evaluierten, ROTEM Parameter ausser ML, waren bei Eitritt signifikant mehr hypokoagulabel im Vergleich zur 24 Stunden Messung.

Hypokoagulabilität ist häufiger in akut traumatisierten Hunden als bisher beschrieben. Nach 6 Stunden nach Trauma waren die Hunde hypo- oder normokoagulabel und der Koagulationsstatus veränderte sich zu Normo- oder Hyperkoagulabilität über die ersten 24 Stunden. Die Gerinnungszeiten, Klotstärke und -entstehungszeit aber nicht die -lyse waren bei Eintritt signifikant verändert im Vergleich zu nach 24 Stunden. Fibrinogenfunktion und -konzentration scheinen eine Rolle in der dynamischen Veränderung des Koagulationsstatus über die ersten 24 Stunden zu spielen.

Gerinnung, Hund, Hyperkoagulabilität, ATC, akute traumatische Koagulopathie 


\title{
Serial Evaluation of Haemostasis Following Acute Trauma Using Rotational Thromboelastometry in Dogs
}

\author{
Yaiza Herrero $^{1}$ Rahel Jud Schefer ${ }^{1}$ Benjamin M. Muri ${ }^{2}$ Nadja E. Sigrist ${ }^{1 \odot}$ \\ ${ }^{1}$ Division of Emergency and Critical Care Medicine, Department of \\ Small Animals, Vetsuisse Faculty of the University of Zurich, Zurich, \\ Switzerland \\ ${ }^{2}$ Clinic for Small Animal Surgery, Department of Small Animals, \\ Address for correspondence Nadja Sigrist, Dr. med. vet., Division of \\ Emergency and Critical Care Medicine, Department of Small Animals, \\ Vetsuisse Faculty, University of Zurich, Winterthurerstrasse 258c, \\ CH-8057 Zurich, Switzerland (e-mail: nsigrist@vetclinics.uzh.ch).
}

Vetsuisse Faculty of the University of Zurich, Zurich, Switzerland

Vet Comp Orthop Traumatol

\begin{abstract}
Keywords

- coagulation

- canine

- hypercoagulopathy

- ATC

- acute traumatic coagulopathy

Objective The aim of this study was to describe the coagulation status of traumatized dogs over the first 24 hours after admission.

Study Design In 33 dogs presenting within 6 hours after trauma blood was sampled for rotational thromboelastometry (ROTEM), thrombocyte number and venous blood gas analysis at presentation and 6 and 24 hours thereafter. At each time point, dogs were defined as hypo-, normo- or hypercoagulable based on extrinsic, intrinsic and fibrinogen ROTEM profiles.

Results Significantly more dogs (11/33) presented hypocoagulable compared with 6 hours $(p=0.046)$ and 24 hours $(p=0.008)$ thereafter and none presented hypercoagulable. Significantly more dogs were hypercoagulable $(6 / 23, p=0.014)$ and no dog was hypocoagulable at 24 hours compared with presentation. All evaluated ROTEM parameters except maximum lysis were significantly more hypocoagulable at presentation compared with 24 hours thereafter.

Conclusion Hypocoagulability is more common in acutely traumatized dogs than previously described. Dogs were hypo- or normocoagulable at presentation and the coagulation status changed to normo- or hypercoagulability over the first 24 hours. Clotting times, clot formation and clot firmness but not clot lysis were significantly altered at presentation compared with 24 hours and fibrinogen concentration or function may play an important role in the dynamic change of coagulation state over time.
\end{abstract}

\section{Introduction}

Trauma has been shown to be associated with an endogenous impairment of coagulation early after trauma and prior to volume resuscitation (acute traumatic coagulopathy, ATC). The encountered hypocoagulability of ATC is distinguished from trauma-induced coagulopathy which includes also resuscitation associated hypocoagulability. ${ }^{1}$ Acute traumatic

received

February 10, 2020

accepted after revision

September 30, 2020 coagulopathy leads to increased mortality and transfusion requirements in people. ${ }^{2}$

So far only a few studies have evaluated the coagulation status of dogs and cats following trauma. ${ }^{3-7}$ The first prospective study, an extensive haemostatic profile in 30 dogs presenting with blunt force trauma, revealed decreased coagulation factor concentrations compared with healthy control dogs. ${ }^{3}$ Further studies in dogs investigating haemostasis by means (c) Georg Thieme Verlag KG Stuttgart · New York
Dol https://doi.org/

$10.1055 / \mathrm{s}-0040-1719167$ ISSN $0932-0814$. 
of plasma coagulation times and/or thromboelastography (TEG) identified hypocoagulability in 0,6 and $15 \%$ of dogs respectively. ${ }^{4-6}$ Former studies primarily identified hypercoagulability, ${ }^{3-5}$ which is in contrast to studies in traumatized people $^{8}$ as well as a recent cat study ${ }^{7}$ and preliminary results in dogs. ${ }^{9}$

Hypercoagulability has been described in people following the hypocoagulable initial phase ${ }^{10,11}$ and is thought to evolve through the close relationship between coagulation, inflammatory and immune responses. ${ }^{12,13} \mathrm{~A}$ recent study in a group of acutely traumatized cats illustrates the dynamic changes in haemostasis from hypocoagulability early after trauma to hypercoagulability within 24 hours. $^{7}$ Given the inconclusive results in previous canine studies and the possibility of a dynamic process being involved in traumarelated coagulopathies, the aim of this study was to describe the coagulation status and selected blood parameters in traumatized dogs at different defined time points after trauma. The goal was to compare results at presentation with those 6 and 24 hours after presentation. Rotational thromboelastometry (ROTEM) was chosen to assess coagulation status as viscoelastic assays offer a global assessment of haemostasis and may be superior to identify both hypoand hypercoagulability than conventional plasma coagulation tests. ${ }^{14,15}$

We presumed that the changes in coagulation status are similar to studies in traumatized people and cats, changing from hypocoagulability to hypercoagulability and that the prevalence of hypocoagulability would be higher early after trauma while 24 hours after trauma hypercoagulability is expected. Our null hypothesis therefore was that coagulation status would not change over time.

\section{Materials and Methods}

The study took place between March 2015 and December 2019 at the Small Animal Clinic of the Vetsuisse Faculty of the University of Zurich and included data acquisition for this study and a concurrent study investigating the differences of clinical signs and laboratory parameters including ROTEM parameters at presentation between dogs with and without ATC. ${ }^{16}$ Dogs presenting within 6 hours after trauma and with owner consent available were eligible to enter the study. The study was approved by the Swiss federal ethics committee on animal research of the Canton of Zurich (ZH023/15).

Exclusion criteria were bodyweight $<3 \mathrm{~kg}$, age $<8$ months, having received any blood products, pharmaceutical agents other than opioids or more than $10 \mathrm{~mL} / \mathrm{kg}$ of intravenous (IV) crystalloid fluid prior to the first blood sampling.

Signalment, type of trauma and time after trauma were collected at presentation. The injury severity was estimated using the animal trauma triage (ATT) score. ${ }^{17}$ Using clinical as well as laboratory parameters at presentation, the acute patient physiologic and laboratory evaluation $\left(\right.$ APPLE $\left._{\mathrm{fast}}\right)$ score $^{18}$ and shock index $(\mathrm{SI}=\mathrm{HR}[\mathrm{Bpm}] /$ systolic BP $[\mathrm{mm}$ $\mathrm{Hg}]^{19,20}$ were calculated and recorded. Higher ATT and APPLE $_{\text {fast }}$ scores indicate more severe injury. ${ }^{17,18}$ Shock was defined as a shock index $\geq 1.0 .^{20}$ Bleeding was defined as presence of haemoperitoneum, haemothorax or significant external bleeding requiring haemostasis at presentation.

Approximately $3 \mathrm{~mL}$ of blood was obtained from the cephalic vein directly after IV catheter placement or by venipuncture of the cephalic or saphenous vein with a $20 \mathrm{G}$ or $22 \mathrm{G}$ needle. Exactly $1.3 \mathrm{~mL}$ blood was collected into $3.8 \%$ sodium citrate tube (Microtube $1.3 \mathrm{~mL}$ 9NC, Sarstedt AG, Nümbrecht, Germany) for ROTEM analysis, $1 \mathrm{~mL}$ in a Li-Heparin tube (Microtube $1.3 \mathrm{~mL}$ 9NC Sarstedt AG, Nümbrecht, Germany) for creatinine, albumin and urea analysis (Fuji Dry-Chem 3500i, Sysmex Suisse AG, Horgen, Switzerland) and $0.5 \mathrm{~mL}$ in a heparinized syringe (BD A-line blood gas syringe, Becton, Dickinson and Company, Plymouth, UK) for venous blood gas analysis (RAPIDPoint 500, Siemens Healthcare, Zürich, Switzerland). ROTEM analysis, venous blood gas analysis and thrombocyte count were performed at presentation and 6 and 24 hours after presentation respectively. Blood samples for these repeated measurements were obtained by venipuncture of the cephalic or saphenous vein with a $20 \mathrm{G}$ or $22 \mathrm{G}$ needle.

The thrombocyte count was estimated manually or using an automated analyser (Sysmex-XT 2000iV, Sysmex Cooperation, Kobe, Japan). The manual platelet count estimates were assessed by using a Wright-Giemsa stain (Diff Quick, Medion Diagnostics, Düdingen, Switzerland) on a citrated whole blood smear, counting the average number of platelets seen per 100x oil immersion high-power field magnification in the monolayer. Ten oil immersion fields were viewed, and the average count multiplied by 15,000 . Samples with moderate-to-severe platelet aggregation were marked accordingly and were defined as normal platelet count $\left(>150 \times 10^{\wedge} 3 / \mu \mathrm{L}\right)$. Thrombocytopenia was defined as a thrombocyte count $<150 \times 10^{\wedge} 3 / \mu \mathrm{L}^{21}$

\section{ROTEM Analysis}

ROTEM analysis (ROTEM Delta, TEM Innovations $\mathrm{GmbH}$, Munich, Germany) was performed 15 to 30 minutes after blood sampling. Citrated blood was kept at $37^{\circ} \mathrm{C}$ using the analysers warming plate after collection. Trained staff performed the tissue factor activated temogram (ex-tem S), ellagic acid activated temogram (in-tem $S$ ) and tissue factor activated temogram with platelet inhibition (fib-tem S) (TEM Innovations $\mathrm{GmbH}$, Munich, Germany) ROTEM analysis according to the manufacturer's instructions and a standardized institutional protocol based on international guidelines. ${ }^{22,23}$ Briefly, $300 \mu \mathrm{L}$ of $37.0^{\circ} \mathrm{C}$ warm, citrated whole blood was incubated for $5 \mathrm{sec}-$ onds with a single portion each of ex-tem $S$, in-tem $S$ and fibtem $S$ reagent (TEM Innovations $\mathrm{GmbH}$, Munich, Germany), followed by transfer of the incubated blood sample into the ROTEM cuvette (Cup and Pin Pro, TEM Innovations $\mathrm{GmbH}$ Munich, Germany) and attaching the cuvette to the pin. An automated pipette was used to transfer the blood sample to be incubated with the reagent and then into the ROTEM cuvette, and samples were analysed for 60 minutes. After measurement, all ROTEM tracings were visually evaluated by the two main authors and excluded if an artifact was suspected. A 'green line' (lack of clot formation) identified in the fib-tem $S$ tracing was defined as a fib-tem maximum clot firmness (MCF) of $0 \mathrm{~mm}$ and a fib-tem clotting time of 3,600 seconds. 


\section{Determination of Coagulation Status}

At each of the three time points (at presentation, 6 and 24 hours after presentation), dogs were grouped as being hypo-, normo- or hypercoagulable. The ex-tem S and in-tem S CT, clot formation time (CFT), maximum clot firmness (MCF) and maximum lysis (ML) as well as fib-tem S MCF were used for determination of coagulation status. A patient was defined as being hypocoagulable at the specific time point if $\geq 2$ parameters in 1 profile and at least another parameter in a second profile of the respective time point were hypocoagulable based on our institutional reference intervals. ${ }^{24}$ Dogs were defined as hypercoagulable at the specific time point if $\geq 2$ parameters in 1 profile and at least another parameter in an additional profile of the respective time point were hypercoagulable. All other dogs were defined as normocoagulable at that time point.

Hyperfibrinolysis was defined as ML above the reference interval in any of the profiles. Hypofibrinogenemia was defined as fib-tem MCF $<2 \mathrm{~mm}$. Transfusion requirement, amount of fluid therapy received within in the first $24 \mathrm{~h}$ of hospitalization, hospital time and survival to hospital discharge were recorded from patient records.

\section{Statistical Methods}

Data from the study protocol and ROTEM database were entered in a spreadsheet. Statistical analysis was performed using IBM SPSS Statistics (for Mac Version 25.0. IBM Corp, Armonk, New York, United States).

Frequencies were recorded via the SPSS program. Continuous data were tested for normality using the Shapiro-Wilk test. Depending on the underlying distribution, mean \pm SD or median and range was listed. Crosstables chi-squared or Fisher's test was used to assess nonparametric data. Group comparisons were made using the $t$-test for two unpaired parametrically distributed datasets or Mann-Whitney U test for unpaired nonparametrically distributed data respectively. Paired $t$-test or Wilcoxon signed-rank test (if the dataset presented a nonparametric distribution) was used to investigate differences of ROTEM parameters over time. If two datasets displayed different distributions, they were both treated as nonparametric data. A $p$-Value $\leq 0.05$ was considered significant.

\section{Results}

A total of 35 dogs were enrolled. Subsequently, two patients were excluded because of treatment with acepromazine or propofol prior to the first blood sampling. All ROTEM profiles of the remaining dogs were included.

Of the 33 dogs included in the study, $8 / 33$ were castrated males, $15 / 33$ intact males, $3 / 33$ castrated females and $7 / 33$ intact females. Mixed breeds were the most common breed (4/33), followed by Spitz (3/33), Dachshund (2/33), Maltese (2/33), Jack Russell Terrier (2/33), Golden Retriever (2/33), Labrador Retriever (2/33), German Shepherd (2/33) and Bichon Frise, Shih Tzu, Boston Terrier, Collie, Whippet, Galgo
Español, Australian Kelpie, Australian Kettle Dog, Husky, Weimaraner, Malinois, White Swiss Shepherd, Labradoodle and Bernese Mountain Dog with 1/33 each. Dogs presented with a body weight between 4 and $44.5 \mathrm{~kg}$ (median $14.6 \mathrm{~kg}$ ) and a median age of 48 months (range, 8-199 months). Nineteen of 33 dogs suffered from blunt force trauma and 14/33 from penetrating trauma. Twenty-eight of 33 dogs had been hit by car, truck, train or tree, 3 dogs had been attacked by another dog and 2 had fallen from height (stairs, out of a window respectively). The first blood sample was taken a median of 115 minutes (range, 15-320 minutes) after trauma.

Nine of 33 dogs had received a maximum of $10 \mathrm{~mL} / \mathrm{kg}$ (range 4-10 mL/kg) Ringer's acetate (Ringer's acetate, Laboratorium Dr. Bichsel AG, Unterseen, Switzerland) prior to blood sampling at presentation. One dog additionally received 5 $\mathrm{mL} / \mathrm{kg} \mathrm{7.2 \%} \mathrm{NaCl}$ (Laboratorium Dr. Bichsel AG, Unterseen, Switzerland). Four of 33 dogs had been treated with buprenorphine (Bupaq P, Streuli Pharma AG, Uznach, Switzerland) and 9/33 with methadone (Methadon Streuli, Streuli Pharma AG, Uznach, Switzerland) before presenting at our ER.

At presentation, the mean \pm SD ATT score was $5 \pm 3$ (range,

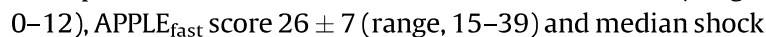
index 1.2 (range, $0.49-5$ ). Nine of 12 dogs presented in shock. Seven of 33 dogs exhibited bleeding at presentation, of which 5 were hypocoagulable. Bleeding was significantly associated with hypocoagulability at presentation but not with the ATT score ( $p=0.027$ and 0.352 respectively). In the first 24 hours, the dogs received a median of $64 \mathrm{~mL} / \mathrm{kg}$ (range, 2-265) Ringer's acetate solution and a median of $33 \mathrm{~mL} / \mathrm{kg}$ (4/33 dogs; range, 3-79) colloids (Voluven, Fresenius Kabi [Schweiz] AG, Kriens, Switzerland). Potassium chloride was added to fluid bags after resuscitation according to a standardized hospital protocol. Six of 33 dogs received a transfusion, 5 of them fresh frozen plasma and one dog red blood cell concentrate. Ten of 33 dogs, of which 3 showed hyperfibrinolysis, were treated with at least one dose $(20 \mathrm{mg} / \mathrm{kg}$ ) of tranexamic acid (Tranexam OrPha, OrPha Swiss GmbH, Küsnacht, Switzerland). The median hospital stay was 3 days (range, 0-42) and 24/33 dogs survived to discharge. Eight of 33 dogs were euthanatized due to a combination of poor prognosis and financial concerns, while 1 dog died in the hospital.

The coagulation status at presentation and over time is shown in - Tables 1 and 2. Eleven of 33 dogs presented with hypocoagulability at initial presentation and 3 of these additionally showed hyperfibrinolysis. No dog presented with hypercoagulability. Significantly more dogs were hypocoagulable at presentation compared with 6 and 24 hours after presentation ( $p=0.046$ and 0.008 respectively), while significantly more $\operatorname{dogs}(6 / 21, p=0.014)$ were hypercoagulable 24 hours after presentation. The dogs that were hypocoagulable at presentation were normocoagulable 6 and 24 hours later. All of the dogs with decreased fib-tem MCF at presentation were hypocoagulable, while hypercoagulable dogs 24 hours after presentation all had a fib-tem MCF above the reference interval. Five of 11 hypocoagulable dogs showed bleeding at presentation and 6 of 7 hypocoagulable dogs that had a shock index performed presented in shock 
Coagulation Status in Traumatized Dogs Herrero et al.

Table 1 ROTEM parameters of 33 dogs at presentation, 6 and 24 hours after acute trauma

\begin{tabular}{|c|c|c|c|c|c|c|c|c|c|c|}
\hline \multirow{2}{*}{$\begin{array}{l}\text { Test } \\
\text { Parameter }\end{array}$} & \multirow[b]{2}{*}{$\begin{array}{l}\text { Reference } \\
\text { interval }\end{array}$} & \multicolumn{2}{|c|}{$\begin{array}{l}\text { At presentation } \\
(n=33)\end{array}$} & \multicolumn{2}{|c|}{6 hours $(n=12)$} & \multicolumn{2}{|c|}{24 hours $^{*}(n=21)$} & \multirow[t]{2}{*}{$p$-Value ${ }^{a}$} & \multirow[t]{2}{*}{$p$-Value ${ }^{b}$} & \multirow[t]{2}{*}{$p$-Value ${ }^{c}$} \\
\hline & & $\begin{array}{l}\text { Mean } \pm \text { SD } \\
\text { median }\end{array}$ & Range & $\begin{array}{l}\text { Mean } \pm S D \\
\text { median }\end{array}$ & Range & $\begin{array}{l}\text { Mean } \pm \text { SD } \\
\text { median }\end{array}$ & Range & & & \\
\hline \multicolumn{11}{|l|}{ Ex-tem $S$} \\
\hline $\mathrm{CT}(\mathrm{s})$ & $23-87$ & 45 & $25-175$ & $43 \pm 19$ & $23-85$ & $28 \pm 7$ & $29-47$ & 0.367 & $<0.001$ & 0.011 \\
\hline CFT (s) & $85-357$ & 229 & $85-3600$ & $176 \pm 64$ & $102-295$ & $135 \pm 64$ & $23-279$ & 0.255 & $<0.001$ & 0.005 \\
\hline $\mathrm{MCF}(\mathrm{mm})$ & $32-65$ & $41 \pm 14$ & $15-66$ & $50 \pm 8$ & $36-61$ & $58 \pm 10$ & $42-76$ & 0.075 & $<0.001$ & 0.005 \\
\hline ML (\%) & $0-12$ & 4 & $0-41$ & $5 \pm 4$ & $0-15$ & $4 \pm 3$ & $0-10$ & 0.123 & 0.099 & 0.572 \\
\hline \multicolumn{11}{|l|}{ In-tem S } \\
\hline$C T(s)$ & $133-210$ & $178 \pm 43$ & $108-275$ & 172 & $135-352$ & 197 & $126-420$ & 0.838 & 0.025 & 0.139 \\
\hline CFT (s) & $59-201$ & 91 & $36-286$ & $102 \pm 47$ & $45-182$ & 80 & $44-160$ & 0.515 & 0.003 & 0.021 \\
\hline $\mathrm{MCF}(\mathrm{mm})$ & $52-71$ & $62 \pm 9$ & $41-85$ & $61 \pm 8$ & $47-71$ & $67 \pm 7$ & $54-80$ & 0.953 & 0.003 & 0.005 \\
\hline ML (\%) & $0-3$ & 0 & $0-41$ & 0 & $0-2$ & 1 & $0-3$ & 0.655 & 0.317 & 0.429 \\
\hline \multicolumn{11}{|l|}{ Fib-tem S } \\
\hline $\mathrm{MCF}(\mathrm{mm})$ & $2-9$ & 4 & $0-15$ & 3.5 & $0-14$ & 9 & $4-30$ & 0.719 & $<0.001$ & 0.016 \\
\hline
\end{tabular}

Abbreviations: CT, clotting time; CFT, clot formation time; ex-tem, tissue factor activated temogram; fib-tem, tissue factor activated temogram with platelet inhibition; in-tem, ellagic acid activated temogram; MCF, maximum clot firmness; ML, maximum lysis; ROTEM, rotational thromboelastometry; SD, standard deviation.

Between presentation and 6 hours after presentation.

between presentation and 24 hours after presentation.

'Between 6 and 24 hours after presentation.

*Eleven of the dogs evaluated at 6 hours were also evaluated at 24 hours.

Table 2 Changes in coagulation status over time in 33 dogs with acute trauma

\begin{tabular}{|l|l|l|l|l|l|}
\hline Time point & At presentation & $\mathbf{6 h}$ & $\mathbf{2 4 h}$ & \multirow{2}{*}{$\boldsymbol{p}$-Value } & \multirow{2}{*}{-Value $^{\mathrm{b}}$} \\
\cline { 1 - 4 } Parameter & $\boldsymbol{n} / \boldsymbol{N}$ & $\boldsymbol{n} / \boldsymbol{N}$ & $\boldsymbol{n} / \boldsymbol{N}$ & & \\
\hline Hypocoagulable & $11 / 33$ & $0 / 12$ & $0 / 21$ & 0.046 & 0.008 \\
\hline Normocoagulable & $22 / 33$ & $12 / 12$ & $17 / 21$ & $\mathrm{NA}$ & $\mathrm{NA}$ \\
\hline Hypercoagulable & $0 / 33$ & $0 / 12$ & $6 / 21$ & 0.317 & 0.014 \\
\hline Hyperfibrinolysis in addition to hypocoagulability & $3 / 11$ & $0 / 12$ & $0 / 21$ & 0.157 & 0.157 \\
\hline Thrombocytopenia & $9 / 32$ & $6 / 7$ & $9 / 13$ & 0.429 & 0.646 \\
\hline
\end{tabular}

Abbreviation: NA, not assessed.

${ }^{\mathrm{a} B e t w e e n ~ p r e s e n t a t i o n ~ a n d ~} 6$ hours after presentation.

between presentation and 24 hours after presentation.

Nine of 32 dogs presented with thrombocytopenia (median 105 ; range, $\left.43-146 \times 10^{\wedge} 3 / \mu \mathrm{L}\right)$. Presence of thrombocytopenia at presentation was not different between hypo- $(3 / 11)$ and normocoagulable $(6 / 22)$ dogs $(p=0.660)$. After 24 hours $5 / 6$ (83\%) hypercoagulable dogs were thrombocytopenic

Blood values at presentation, after 6 and 24 hours, are summarized in - Table 3. Haematocrit was significantly lower 6 and 24 hours after presentation compared with at presentation ( $p=0.017$ and 0.002 respectively). The base excess was significantly lower at presentation compared with 6 hours later $(p=0.008)$. Lactate levels decreased significantly between presentation and 24 hours and 6 and 24 hours $(p=0.001$, 0.037 ) respectively. Twenty of 31 dogs presented with a lactate $>2 \mathrm{mmol} / \mathrm{L}$. Potassium was significantly lower at 6 hours compared with 24 hours $(p=0.025$ ) and bicarbonate significantly higher comparing initial values with the 6 and 24 hours results ( $p=0.008$ and $p=0.021$ respectively).
Comparing the hypercoagulable dogs at 24 hours with the normocoagulable dogs, no significant differences were found in the amount of fluid administered, tranexamic acid treatment or transfusions received $(p=0.622,0.183$ and 0.137 respectively).

\section{Discussion}

Traumatized dogs evaluated within 6 hours after trauma were hypo- or normocoagulable at presentation and coagulation status changed independent of treatment to a normo- or hypercoagulable state within 24 hours after presentation. Clotting times, clot formation and clot firmness but not clot lysis were significantly hypocoagulable at presentation compared with 24 hours after presentation. Only 3 of 11 hypocoagulable dogs showed hyperfibrinolysis at presentation. Most dogs presenting hypocoagulable showed a decreased 


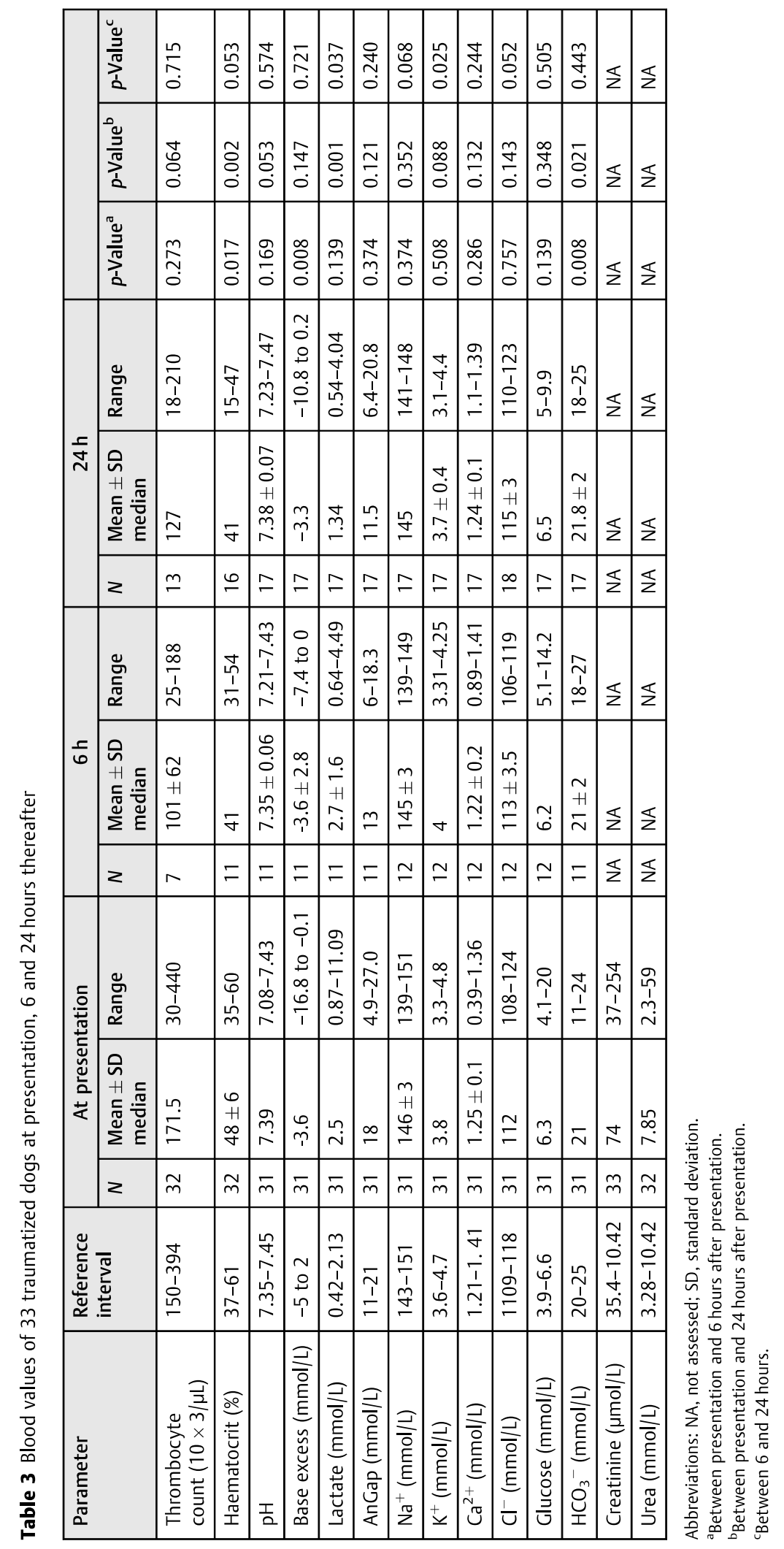


fibrinogen concentration or function, while the hypercoagulable dogs 24 hours after presentation had an increased fibrinogen clot firmness.

Our study reports a higher prevalence of hypocoagulability in dogs than previously reported $(0-15 \%){ }^{3-6}$ In contrast to previous studies in both dogs $s^{3,4}$ and cats, ${ }^{5,7}$ none of the dogs of our study population showed hypercoagulability at presentation. While mean/median ROTEM parameters were within RI at all three evaluated time points (at presentation, 6 and 24 hours thereafter), all evaluated ROTEM parameters except ML were significantly more hypocoagulable at presentation compared with 24 hours later, indicating that there was a change in both clot formation and clot strength over time. While previous studies in dogs describe lower coagulation factor activities in traumatized dogs, ${ }^{3,6}$ ROTEM analysis in traumatized people and animal models ${ }^{25}$ considers reduced clot strength as the main contributor to trauma-related hypocoagulability. ${ }^{26-28}$ Clot firmness primarily depends on thrombocyte number and fibrinogen concentration and function. Thrombocytopenia was common at all time points and was equally identified in hypo- and normocoagulable dogs at presentation as well as in hypercoagulable dogs 24 hours after presentation, suggesting other reasons than thrombocytopenia for clot strength abnormalities in traumatized dogs. In people, trauma patients suffer from severe fibrinogen depletion and fibrinogen seems to be the most vulnerable coagulation factor, reaching critically low levels earlier than others. ${ }^{29}$ Fib-tem S MCF strongly correlates with fibrinogen concentration $^{30,31}$ and was significantly lower at presentation compared with 24 hours after presentation, indicating that fibrinogen concentration and function may be the main determinant of reduced clot strength and hypocoagulability in traumatized dogs presented early after trauma. The pathophysiology of fibrinogen depletion in trauma patients has not been identified as of yet. Loss due to bleeding, consumption through extensive exposure to tissue factor in the case of hypoperfusion, hyperfibrinolysis and decreased availability as a result of acidosis and hypothermia are proposed mechanisms. ${ }^{29}$ Shock and hypoperfusion as well as clinical signs of bleeding were identified in the majority of hypocoagulable dogs and may represent possible reasons for decreased fib-tem $\mathrm{S}$ clot strength and hypocoagulability in our study population. Interestingly, decreased fibrinogen clot firmness was not common in traumatized cats with hypocoagulability. ${ }^{7}$

Hyperfibrinolysis is described as an important consequence of ATC in people, while it does not seem to be a common finding in cats. ${ }^{7}$ We only identified $9 \%$ of dogs with hyperfibrinolysis and hyperfibrinolysis was only identified at presentation. The low grade of trauma severity (ATT score $5 \pm 3$ ) is a possible reason for the low prevalence of hyperfibrinolysis, as trauma severity and shock are associated with protein $C$ activation and hyperfibrinolysis. ${ }^{32}$

Hypocoagulability was only identified at presentation and dogs that presented with hypocoagulability became normocoagulable within 24 hours after presentation. As shown in people $^{33}$ and cats, ${ }^{7}$ our results indicate that trauma-induced changes in coagulation are dynamic and change from hypocoagulability to hypercoagulability over 24 hours despite fluid therapy and haemodilution (seen by the significant decrease in haematocrit). We do not suspect the reduction in haematocrit is causing the hypercoagulability, ${ }^{34}$ as mean/median haematocrits remained within the RI. Potentially, both transfusion therapy and administration of tranexamic acid could lead to hypercoagulopathy. However, no studies have evaluated the effect of transfusion- or antifibrinolytic therapy on clot strength. Furthermore, transfusion requirements and tranexamic acid application were not different between normo- and hypercoagulable dogs 24 hours after presentation.

The dynamic changes in coagulation status after trauma are not well understood. In people, hypoperfusion leads to thrombomodulin expression by the endothelium which complexes with thrombin and activates protein C. Activated protein $\mathrm{C}$ inhibits Factor VIII and Factor V and inactivates tissue plasminogen activator inhibitor-1, leading to hypocoagulability and hyperfibrinolysis. ${ }^{35,36}$ The following rapid change to a state of protein $C$ depletion is characterized by hypercoagulability and has been shown to occur between 6 and 24 hours after injury. ${ }^{13}$ Therefore, depending on the degree of activation of haemostasis, time point of analysis and other confounding factors, trauma patients can present hypo-, hyper-, or normocoagulable.

Three quarters of dogs presented in shock (shock index $>1$ ) and two thirds with hyperlactatemia, rendering hypoperfusion a possible initiator of protein C pathway activation followed by consumption. While we did not measure activated protein $C$ concentrations, a study investigating traumatized dogs identified decreased activated protein $C$ activity together with hypocoagulability and normal activity together with hypercoagulability, further indicating that other pathomechanisms may be relevant in coagulation abnormalities encountered in dogs after trauma. ${ }^{3}$ Our results indicate that fibrinogen concentration/function are important players in the dynamic changes as well because all of the dogs showing hypercoagulability at 24 hours had a fib-tem MCF above the reference interval. Being an acute phase protein, fibrinogen is expected to increase after trauma and may be the reason for the encountered change toward hypercoagulability. ${ }^{3}$

Our results are of clinical interest showing that the prevalence of hypocoagulability after trauma is higher than previously reported but that within 24 hours after trauma, hypocoagulability is expected to be rare to absent. A concurrent study ${ }^{16}$ is investigating the differences between hypo- and normocoagulable dogs at presentation and possible associations with clinical and laboratory parameters that may predict hypocoagulability.

Several limitations of our study need to be discussed. Due to logistic reasons, not all dogs could be analysed at the 6 and 24 hours time points. Despite the small number of dogs, significant changes were detected between presentation and 24 hours, indicating that sample size was large enough. Some dogs received crystalloid fluid therapy or opioids prior to the first blood sampling, which mimics the clinical situation. Ringer's acetate administration in the doses administered to our dogs is expected to have a minimal effect on ROTEM parameters. ${ }^{37}$ The effect of methadone on ROTEM parameters is unknown. As an additional limitation, sampling site and 
technique, evaluation of clinical status and handling of the ROTEM device were standardized as much as possible but were not always executed by the same physician. Differences in sampling technique and site of sampling can influence the ROTEM tracings, and consequently, the study results. ${ }^{23}$ Again, this represents the clinical situation of an emergency clinic and should be incorporated in clinical studies.

\section{Conclusion}

The coagulation status of traumatized dogs changes over time. Hypocoagulability early after trauma is more common than previously described. In contrast to previous studies, no dog presented hypercoagulable. Significantly more dogs were hypocoagulable at presentation compared with 24 hours thereafter, while at 24 hours, significantly more dogs were hypercoagulable, and no dog was hypocoagulable despite fluid therapy and potential haemodilution. Our results suggest a role of fibrinogen concentration and/or function as the cause of initial hypocoagulability and later hypercoagulability. Hyperfibrinolysis was identified in only three dogs.

\section{Note}

This study was presented in part as a poster at the 17 th European Veterinary Emergency and Critical Care congress in Venice, Italy, June 21, 2018.

\section{Authors' Contributions}

All authors contributed to conception of study, study design, acquisition of data, data analysis and interpretation, and drafting/revising and approving the submitted manuscript. They drafted/revised and approved the submitted manuscript. They are publically accountable for relevant content.

\section{Funding}

This study was partly funded by the Small Animal Foundation of the Vetsuisse Faculty (Intern salary and ROTEM material), and Axonlab AG, Baden, Switzerland (discount on ROTEM material)

\section{Conflict of Interest}

None declared.

\section{References}

1 Kushimoto S, Kudo D, Kawazoe Y. Acute traumatic coagulopathy and trauma-induced coagulopathy: an overview. J Intensive Care 2017;(05):6

2 Davenport RA, Brohi K. Cause of trauma-induced coagulopathy. Curr Opin Anaesthesiol 2016;29(02):212-219

3 Mischke R. Acute haemostatic changes in accidentally traumatised dogs. Vet J 2005;169(01):60-64

4 Abelson AL, O'Toole TE, Johnston A, Respess M, de Laforcade AM. Hypoperfusion and acute traumatic coagulopathy in severely traumatized canine patients. J Vet Emerg Crit 2013;23(04): 395-401

5 Gottlieb DL, Prittie J, Buriko Y, Lamb KE. Evaluation of acute traumatic coagulopathy in dogs and cats following blunt force trauma. J Vet Emerg Crit Care 2017;27(01):35-43
6 Holowaychuk MK, Hanel RM, Darren Wood R, Rogers L, O'Keefe K, Monteith G. Prospective multicenter evaluation of coagulation abnormalities in dogs following severe acute trauma. J Vet Emerg Crit Care 2014;24(01):93-104

7 Muri BM, Jud Schefer R, Sigrist NE. Serial evaluation of haemostasis following acute trauma using rotational thromboelastometry in cats. Vet Comp Orthop Traumatol 2019;32(04): 289-296

8 Spahn DR, Bouillon B, Cerny V, et al. The European guideline on management of major bleeding and coagulopathy following trauma: fifth edition. Crit Care 2019;23(01):98

9 Sigrist NE, Herrero Y, Muri B, Jud Schefer R. Serial evaluation of haemostasis by rotational thromboelastometry (ROTEM) in dogs with acute trauma. J Vet Emerg Crit Care 2018;28:35

10 Gando S. Acute coagulopathy of trauma shock and coagulopathy of trauma: a rebuttal. You are now going down the wrong path. J Trauma 2009;67(02):381-383

11 Hess JR, Brohi K, Dutton RP, et al. The coagulopathy of trauma: a review of mechanisms. J Trauma 2008;65(04):748-754

12 Dobson GP, Letson HL, Sharma R, Sheppard FR, Cap AP. Mechanisms of early trauma-induced coagulopathy: the clot thickens or not? J Trauma Acute Care Surg 2015;79(02):301-309

13 Kornblith LZ, Moore HB, Cohen MJ. Trauma-induced coagulopathy: the past, present, and future. J Thromb Haemost 2019;17 (06):852-862

14 Brohi K, Cohen MJ, Davenport RA. Acute coagulopathy of trauma: mechanism, identification and effect. Curr Opin Crit Care 2007;13 (06):680-685

15 Rugeri L, Levrat A, David JS, et al. Diagnosis of early coagulation abnormalities in trauma patients by rotation thromboelastography. J Thromb Haemost 2007;5(02):289-295

16 Herrero Y, Jud Schefer R, Muri B, Sigrist NE. Prevalence of acute traumatic coagulopathy in acutely traumatized dogs and association with clinical and laboratory parameters at presentation. Vet Comp Orthop Traumatol 2020 (in press)

17 Rockar RA, Drobatz KS, Shofer FS. Development of a scoring system for the veterinary trauma patient. J Vet Emerg Crit Care 1994;4:77-83

18 Hayes G, Mathews K, Doig G, et al. The acute patient physiologic and laboratory evaluation (APPLE) score: a severity of illness stratification system for hospitalized dogs. J Vet Intern Med 2010;24(05):1034-1047

19 Peterson KL, Hardy BT, Hall K. Assessment of shock index in healthy dogs and dogs in hemorrhagic shock. JVet Emerg Crit Care 2013;23(05):545-550

20 Porter AE, Rozanski EA, Sharp CR, Dixon KL, Price LL, Shaw SP. Evaluation of the shock index in dogs presenting as emergencies. J Vet Emerg Crit Care 2013;23(05):538-544

21 Bauer N, Kraft W, Moritz A. Klinische Labordiagnostik in der Tiermedizin. 7th edition. Stuttgart: Schattauer; 2014(Anhang) 51

22 deLaforcade A, Goggs R, Wiinberg B. Systematic evaluation of evidence on veterinary viscoelastic testing part 3 : assay activation and test protocol. J Vet Emerg Crit Care 2014;24(01):37-46

23 Flatland B, Koenigshof AM, Rozanski EA, Goggs R, Wiinberg B. Systematic evaluation of evidence on veterinary viscoelastic testing part 2: Sample acquisition and handling. J Vet Emerg Crit Care 2014;24(01):30-36

24 Jud Schefer R, Heimgartner L, Stirn M, Sigrist NE. Determination of reference intervals for single vial rotational thromboelastometry (ROTEM) parameters and correlation with plasmatic coagulation times in 49 clinically healthy dogs. Res Vet Sci 2020;129:129-136

25 Frith D, Cohen MJ, Brohi K. Animal models of trauma-induced coagulopathy. Thromb Res 2012;129(05):551-556

26 Rizoli SB, Scarpelini S, Callum J, et al. Clotting factor deficiency in early trauma-associated coagulopathy. J Trauma 2011;71(05, Suppl 1):S427-S434

27 Johansson PI, Ostrowski SR. Acute coagulopathy of trauma: balancing progressive catecholamine induced endothelial activation and 
damage by fluid phase anticoagulation. Med Hypotheses 2010;75 (06):564-567

28 Davenport $\mathrm{R}$, Khan $\mathrm{S}$. Management of major trauma haemorrhage: treatment priorities and controversies. $\mathrm{Br} \mathrm{J}$ Haematol 2011;155(05):537-548

29 Schlimp CJ, Schöchl H. The role of fibrinogen in trauma-induced coagulopathy. Hamostaseologie 2014;34(01):29-39

30 Enk NM, Kutter APN, Kuemmerle-Fraune C, Sigrist NE. Correlation of plasma coagulation tests and fibrinogen Clauss $_{\text {with rotational }}$ thromboelastometry parameters and prediction of bleeding in dogs. J Vet Intern Med 2019;33(01):132-140

31 Rourke C, Curry N, Khan S, et al. Fibrinogen levels during trauma hemorrhage, response to replacement therapy, and association with patient outcomes. J Thromb Haemost 2012;10(07): 1342-1351

32 Kutcher MEM, Ferguson ARP, Cohen MJM. A principal component analysis of coagulation after trauma. J Trauma Acute Care Surg 2013;74(05):1223-1229, discussion 1229-1230
33 Duan K, Yu W, Li N. The pathophysiology and management of acute traumatic coagulopathy. Clin Appl Thromb Hemost 2015;21 (07):645-652

34 Smith SA, McMichael MA, Gilor S, Galligan AJ, Hoh CM. Correlation of hematocrit, platelet concentration, and plasma coagulation factors with results of thromboelastometry in canine whole blood samples. Am J Vet Res 2012;73(06):789-798

35 Cohen MJ, Kutcher M, Redick B, et al; PROMMTT Study Group. Clinical and mechanistic drivers of acute traumatic coagulopathy. J Trauma Acute Care Surg 2013;75(01, Suppl 1):S40-S47

36 Brohi K, Cohen MJ, Ganter MT, Matthay MA, Mackersie RC, Pittet JF. Acute traumatic coagulopathy: initiated by hypoperfusion: modulated through the protein C pathway? Ann Surg 2007;245 (05):812-818

37 Reuteler A, Axiak-Flammer S, Howard J, Adamik KN. Comparison of the effects of a balanced crystalloid-based and a saline-based tetrastarch solution on canine whole blood coagulation and platelet function. J Vet Emerg Crit Care 2017;27(01):23-34 


\section{Danksagung}

An dieser Stelle möchte ich allen Personen, die mich bei der Anfertigung meiner Dissertation unterstützt haben, meinen Dank aussprechen.

Insbesondere Nadja Sigrist für die herzliche und geduldige Betreuung, Benjamin Muri und Rahel Jud für die Mitwirkung, sowie allen anderen Personen, die mich bei der Probengewinnung unterstützt haben. 


\title{
Curriculum Vitae
}

\begin{tabular}{|c|c|}
\hline Vorname Name & Yaiza Herrero \\
\hline Geburtsdatum & 05.04.1993 \\
\hline Geburtsort & Flawil \\
\hline Nationalität & Schweizerisch / Spanisch \\
\hline Heimatort bei Schweizer/-in & Häggenschwil \\
\hline \multirow[t]{2}{*}{$08 / 99-06 / 08$} & Primarschule und Sekundarschule \\
\hline & Primarschule und Oberstufe Kirchstrasse, Uzwil, Schweiz \\
\hline \multirow[t]{2}{*}{$08 / 08-06 / 11$} & Ausbildung zur Fachfrau Betreuung Gerontologie \\
\hline & Seniorenzentrum Uzwil, Uzwil, Schweiz \\
\hline \multirow[t]{2}{*}{$06 / 13$} & Berufsmaturität \\
\hline & freie BM-Prüfung, Bern, Schweiz \\
\hline \multirow[t]{3}{*}{$08 / 13-08 / 14$} & Passerelle \\
\hline & Interstaatliche Maturitätsschule für Erwachsene, St.Gallen, \\
\hline & Schweiz \\
\hline \multirow[t]{3}{*}{$08 / 14$} & Matura \\
\hline & Passerelle, Interstaatliche Maturitätsschule für Ewachsene, \\
\hline & St.Gallen, Schweiz \\
\hline \multirow[t]{2}{*}{$09 / 14-09 / 19$} & Studium \\
\hline & Veterinärmedizin, Vetsuisse-Fakultät Zürich, Schweiz \\
\hline
\end{tabular}

Vetsuisse-Fakultät Zürich, Schweiz

$12 / 19-03 / 20$

\author{
Anfertigung der Dissertation \\ unter Leitung von Prof. Dr. med. vet. Antonio Pozzi, Dipl. \\ ECVS / ACVS und ACVSMR \\ am Departement für Kleintiere \\ der Vetsuisse-Fakultät Universität Zürich \\ Vorsteher: Prof. Dr. med. vet Antonio Pozzi, Dipl. ECVS / ACVS \\ und ACVSMR
}

03/20 - heute

\section{Assistenzärztin (Internship)}

Abteilung für Notfall- und Intensivmedizin am Tierspital Zürich

Vetsuisse-Fakultät Zürich, Schweiz 